\title{
What controls tropical reef fish populations: recruitment or benthic mortality? An example in the Caribbean reef fish Haemulon flavolineatum
}

\author{
M. J. Shulman*, J. C. Ogden \\ West Indies Laboratory, Fairleigh Dickinson University, Teague Bay, Christiansted, St. Croix, U. S. Virgin Islands 00820, USA
}

\begin{abstract}
Recruitment from a planktonic larval stage has been proposed to be an important factor in limiting populations of marine organisms, particularly tropical reef fishes. We monitored recruitment and population densities of juvenile size classes in French grunt Haemulon flavolineatum (Haemulidae) from October 1978 through December 1980 in a portion of Tague Bay, St. Croix, U. S. Virgin Islands. Within our study area, $95 \%$ of new recruits settled onto the sand and seagrass lagoon floor and within a few weeks migrated to nearby reefs; the remaining $5 \%$ settled directly onto reef structures. Mean annual recruitment rate was 1.8 recruits per $\mathrm{m}^{2}$ of lagoon floor, equivalent to 44 recruits per $\mathrm{m}^{2}$ of juvenile (backreef) habitat per yr and among tho highest recruitment rates yet reported for reef fishes. Post-settlement mortality was also very high: during the first month of benthic life it was 0.9 and during the first year was $>0.992$. We propose a sensitivity analysis criterion for determining the relative influence of multiple factors or processes that limit adult population size. The criterion we used is the relative sensitivity of adult population size to proportionate changes in those factors or processes. Using an open, density-independent model of benthic population dynamics for French grunts, we estimate that changes in post-recruitment mortality rate will have a 100 times greater effect on the abundance of large juveniles than a proportionate change in recruitment rate. Therefore we conclude that, whether or not mortality is density-independent, the factors controlling benthic mortality are much more important in the benthic population dynamics of French grunts than is the recruitment rate. The same analysis is applied to other coral reef fishes for which appropriate data are available; we conclude that for 2 out of 3 species for which recruitment limitation has been demonstrated, changes in benthic mortality are likely to have a stronger influence on adult population sizes than are proportionately equivalent changes in recruitment rate.
\end{abstract}

\section{INTRODUCTION}

Many marine organisms have 2 life history stages, one benthic and one planktonic. Several recent studies have suggested that, in at least some, and perhaps many, of these species, benthic populations are limited by recruitment from the planktonic stage (Williams 1980, Yoshioka 1982, Doherty 1983, Victor 1983, Underwood \& Denley 1984, Gaines \& Roughgarden 1985, Wellington \& Victor 1985). The ramifications of recruitment limitation for population and community ecology are many. Recruitment limitation implies a control of benthic population dynamics by recruitment rates rather than by physical and bio-

\footnotetext{
- Present address: Department of Biology, University of California, Los Angeles, California 90024, USA
}

logical factors directly affecting the benthic life stage.

Coral reef fishes are among those marine animals for which recruitment limitation has been suggested to exist. Relatively little information is available on recruitment and post-settlement mortality in reef fishes, but 4 recent studies have suggested that recruitment rates may be controlling adult population sizes in several species (Williams 1980, Doherty 1983, Victor 1983. Wellington \& Victor 1985). In this report, we present the results of a $2 \frac{1 / 4}{4}$ r study on recruitment and population dynamics in the Caribbean reef fish Haemulon flavolineatum (Haemulidae). The aims of the paper are: (1) to examine recruitment rates and post-recruitment mortality in this species, and (2) to consider whether recruitment or the factors determining post-recruitment mortality have the greater influence on adult population size. We present a criterion 
and a model for comparing the relative strengths of recruitment and post-recruitment mortality

Almost all species of fishes living on tropical reefs have a planktonic life history phase (Sale 1980). The French grunt Haemulon flavolineatum has both a pelagic egg as well as a pelagic larva. Planktonic life (zygotic and larval) lasts an average of $14 \mathrm{~d}$ (Brothers \& McFarland 1981, McFarland et al. 1985) at which time the larvae settle into sand or seagrass habitats (Shulman 1985a) or onto reef structures (McFarland et al. 1985) and begin their benthic life. Those juveniles settling into sand or seagrass habitats migrate to reefs within the first month after settlement (Shulman 1985a). During the benthic part of their life cycle, French grunts spend daylight hours in monotypic and heterotypic schools on the reef (Ogden \& Ehrlich 1977). After the first $2 \mathrm{wk}$ of benthic life, French grunts migrate at twilight into sand or seagrass areas, returning to their schooling sites at dawn (Ogden \& Ehrlich 1977. McFarland et al. 1979, Helfman et al. 1982). From settlement until they attain sizes of 30 to $40 \mathrm{~mm}$ standard length (SL), French grunts feed during the day on plankton (Helfman et al. 1982, McFarland pers. comm.). At that point they make the transition to the adult pattern of feeding solitarily at night on benthic invertebrates that occupy the sand and seagrass habitats (Robblee 1986). French grunts become sexually mature at 120 to $150 \mathrm{~mm}$ SL (Billings \& Munro 1974). Spawning has not been observed in this species and spawning behaviors and frequencies are not known.

\section{MATERIALS AND METHODS}

Study area. This research was conducted in Tague Bay, on the northeast coast of St. Croix, United States Virgin Islands. The bank-barrier reef, which encloses Tague Bay, has been described by Ogden (1972) and
Adey (1975). Our reef study site (Fig. 1) was a $300 \mathrm{~m}$ long section of the backreef of Tague Bay reef. This particular section was chosen because the habitat is relatively uniform along its length and because there are no patch reefs nearby in the lagoon. The backreef zone is composed of colonies of Acropora palmata, Porites porites, Montastrea annularis, smaller head corals, and consolidated coral rubble. The width of the backreef (from lagoon edge to reef crest) varies from 4 to $15 \mathrm{~m}(\overline{\mathrm{X}}=8.9 \mathrm{~m})$. The lagoon floor stretching south from our study site is 5 to $8 \mathrm{~m}$ in depth and covered with sand mounds produced by the activities of the thalassinid shrimps, Callianassa spp. The dominant flora on the lagoon floor are the seagrasses Syringodium filiforme and Halodule wrightii, the calcareous green algae Penicillis spp. and Halimeda spp., and the fleshy algae Dictyota and Acanthophora spp.

Reef population censuses. The study took place from October 1978 through December 1980. During this period, French grunts Haemulon flavolineatum within the study site were censused from 1 to 11 times $\mathrm{mo}^{-1}$ ( $\overline{\mathrm{X}}$ $=3.3$ censuses $\mathrm{mo}^{-1}$ ) with the exception of January 1980 when no censuses were taken. Thirty-three schooling sites were found within the reef study area; not all were occupied at all times over the 27 mo period of the study. At each census, the numbers of individuals in each of 5 size classes in each school were recorded. During the first month of the study, censuses were made by 2 divers; these censuses were compared and the censusing estimates of the 2 observers were calibrated. All following censuses were made by only one diver. The number of grunts at any one schooling site ranged from 0 to 900 . Through multiple censuses and comparisons of censuses by 2 divers, we estimate that the error in censuses for school sizes up to 100 was approximately $10 \%$ while that for larger schools was as much as $20 \%$.

The grunt schools in our reef study area consisted almost solely of French grunts. Only occasional white
Fig. 1 Location of study within Tague Bay on the northeast coast of St. Croix, U. S. Virgin Islands. Stippled section is the portion of the backreef of Tague Bay Reef within which we censused French grunt schools. The $150 \mathrm{~m}$ long Lagoon Transect, $20 \mathrm{~m}$ from the backreef and parallel to it, was censused for newly settled French grunt recruits. Area marked with diagonal lines represents the part of the lagoon considered the source area for recruiting French grunts that would migrate to the reef study area

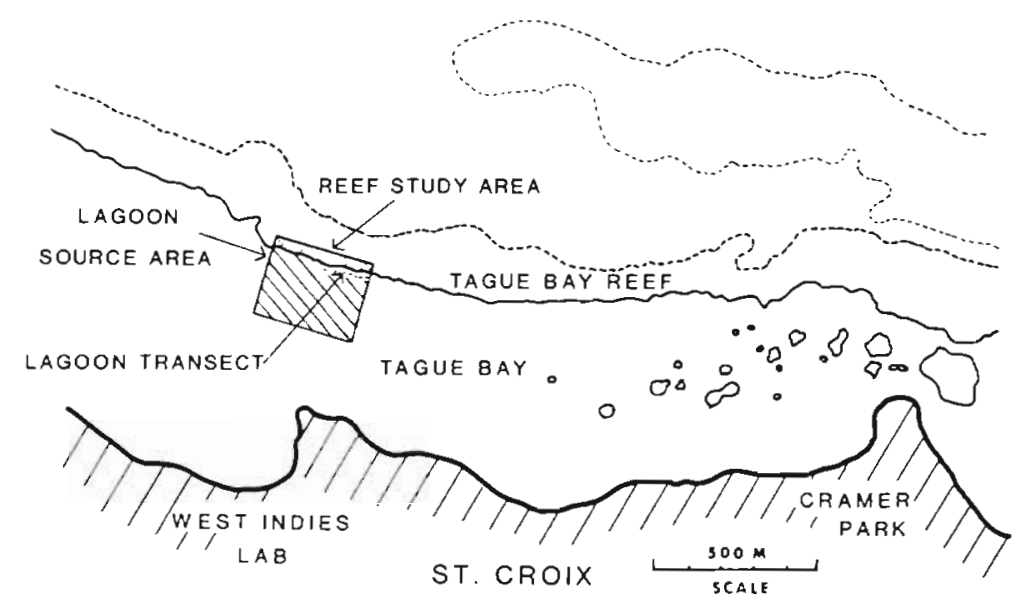


grunts Haemulon plumieri, juvenile mahogany snappers Lutjanus mahogoni, and juvenile yellowtail snappers Ocyurus chrysurus were observed in the schools. In other areas French grunts were commonly observed in heterotypic schools.

The 5 size classes (recruit, small juvenile, medium juvenile, large juvenile, adult: Table 1) used in the censuses were similar but not identical to those used by Brothers \& McFarland (1981) and Helfman et al. (1982). The age ranges (Table 1) for sizes up to $100 \mathrm{~mm}$ standard length were determined for French grunts through otolith aging by Brothers \& McFarland (1981). Ages for size classes above $100 \mathrm{~mm}$ were estimated from the age/growth curves presented in Billings \& Munro (1974).

Lagoon recruit censuses. In addition to censuses of schools on the reef, newly settled French grunts were censused in the nearby lagoon. A $150 \mathrm{~m}$ long transect marked with steel stakes was set up parallel to the eastern half of the reef study area and $20 \mathrm{~m}$ into the lagoon (Fig. 1). From November 1978 to December 1980, all grunts within $5 \mathrm{~m}$ of each side of the lagoon transect line were visually censused an average of 4 times $\mathrm{mo}^{-1}$ from May to December and 2 times $\mathrm{mo}^{-1}$ from January to April each year.

\section{DATA ANALYSIS}

Estimates of recruit abundance. Post-larval grunts settle in sand, seagrass, and reef habitats. Individuals settling in sand or seagrass usually migrate to reefs before they are 1 mo old (Shulman 1985a, this paper). French grunts settling in Tague Bay can migrate to the bank-barrier reef, a fringing reef, or a patch reef (Fig. 1). To determine the number of settling post-larval grunts that were potential recruits to our reef study area, we included all post-larvae settling in lagoonal areas for which our reef study area was the closest reef. This represents the population of recruits settling in the section of the lagoon extending $210 \mathrm{~m}$ out perpendicularly from our reef study area. We will refer to this portion of Tague Bay as the 'lagoon source area' (Fig. 1).
To estimate the abundance of recruits in the lagoon source area, in October 1985 we ran $150 \mathrm{~m}$ long, $10 \mathrm{~m}$ wide transects at distances of $10,20,40,60,80,100,150$ $m$ from, and parallel to, the reef study area. Total abundance of recruits in the lagoon source area was estimated by linear interpolation and summation over the whole area. The ratio between the total abundance and abundance in the lagoon transect $20 \mathrm{~m}$ from the reef was used to estimate the number of grunt recruits present in the lagoon source area for the dates on which the regular $20 \mathrm{~m}$ transects were made.

French grunt settlement occurs on a semilunar cycle with peaks of settlement on the quarter moons (McFarland et al. 1985). To estimate the number of recruits settling each lunar month, we determined the census date that was closest to the date of each quarter moon and summed the number of recruits present at those 2 censuses. If no census was made within a $3 \mathrm{~d}$ period around a quarter moon date then the abundance of recruits for that quarter moon was determined by linear interpolation between the nearest quarter moon abundances. Interpolation was required for 11 of the 52 quarter moon periods; 4 of those 11 occurred during winter when recruitment was extremely low (see 'Results'). French grunts grow out of the recruit size class within $16 \mathrm{~d}$ (Table 1) and older, larger recruits can be easily distinguished from newly settled individuals. Therefore, few or no grunts would have been counted as newly settled recruits in more than one quarter moon census.

Estimates of inter-size class survivorship. Survivorship between size classes was estimated by comparing the abundances of each size class within lagged annual periods. The number of postlarvae settling in a year period was estimated by summing up the recruits present on all quarter moons within that year. The numbers of individuals present in each of the other size classes were determined using the following method. The number of individuals present on each day of the year was estimated by linear interpolation between the census dates. The numbers of recruit-days, small juvenile-days, and large juvenile-days were then calculated by summing the numbers of individuals in each size class present on each day of the annual period. The

Table 1. Haemulon flavolineatum. Size categories and their estimated age ranges for French grunts. Sources for the age ranges are given in the text

\begin{tabular}{|lcccc|}
\hline Size category & SL size range $(\mathrm{mm})$ & Otolith age range $(\mathrm{d})$ & Age past settlement (d) & No. of days in size class \\
\hline Recruits & $5-15$ & $14-30$ & $0-16$ & 16 \\
Small juveniles & $15-25$ & $30-55$ & $16-41$ & 25 \\
Medium juveniles & $25-60$ & $55-175$ & $41-161$ & 120 \\
Large juveniles & $60-120$ & $175-450$ & $161-436$ & 275 \\
Adults & $>120$ & $>450$ & $>436$ & - \\
\hline
\end{tabular}


'size-class-days' were then divided by the number of days an individual would spend in each size class (Table 1) and the resulting value was used as the estimate for the number of individuals in that size class present in the annual period.

Survivorship between 2 adjacent size classes was calculated by dividing the annual period abundance of the older size class by that of the younger. Lagged annual periods were used: the annual period of the older size class would lag behind that of the younger size class by the number of days which individuals spent in the younger size class. Three estimates of survivorship were made, each with a different starting date (28 Oct 1978; 1 Jan 1979; 1 Mar 1979) for estimates of annual recruit abundance.

Despite the large number of juveniles present in our reef study area, only a few adult French grunts were ever observed there. Adult French grunts were much more common in deeper coral habitats on the Tague Bay forereef. These deeper areas had relatively few French grunts of recruit or juvenile size classes. Because of the distributions of size classes, we assumed that French grunts, on reaching reproductive size, emigrated from our reef study area into deeper water habitats. Therefore, we do not make an estimate of survivorship from the large juvenile to the adult sizes from our reef study area census data.

\section{RESULTS}

\section{Population dynamics}

The total population of French grunts in the reef study area and the lagoon source area varied widely over the $2 \frac{1}{4}$ yr period (Fig. 2). Peaks in the total number of individuals occurred in November 1978, September 1979, and November 1980. These peaks ranged from 2861 to 3474 individuals in the reef study area or 1.1 to 1.3 French grunts per $\mathrm{m}^{2}$ of backreef. The lows in total number occurred in February through June 1979 and November through May 1980 and ranged from 189 to $898\left(0.07\right.$ to 0.35 ind $\left.\mathrm{m}^{-2}\right)$. Total population size varied by a factor of 6.9 within 1979 and 18 within 1980 .

Settlement of post-larval grunts was extremely low during December, January and February and highest in the period of May through November. This pattern was consistent over the 2 yr period. However, in 1979, recruitment occurred at moderate rates throughout the period of highest settlement while in 1980 recruitment occurred at lower rates for most months and then rose to a high in September. Within one year, settlement varied from a low of 0 recruits in January and February to a high of $32400 \mathrm{in}$ September. Between years, settlement in the same lunar month varied by factors of 1.4 to 12.9 during the May to November period of high recruitment.

On an annual basis, recruitment rates were very high. Over any given 12 mo period within our $26 \mathrm{mo}$ study, 84000 to $140000(\overline{\mathrm{X}}=118000)$ French grunts recruited to the study reef or the lagoon source area. This is equivalent to 1.3 to 2.1 recruits per $\mathrm{m}^{2}$ of lagoon floor or 32 to 53 per $\mathrm{m}^{2}$ of backreef per yr The vast majority $(95 \%)$ of the recruits initially settled in the lagoon rather than settling directly onto the reef.
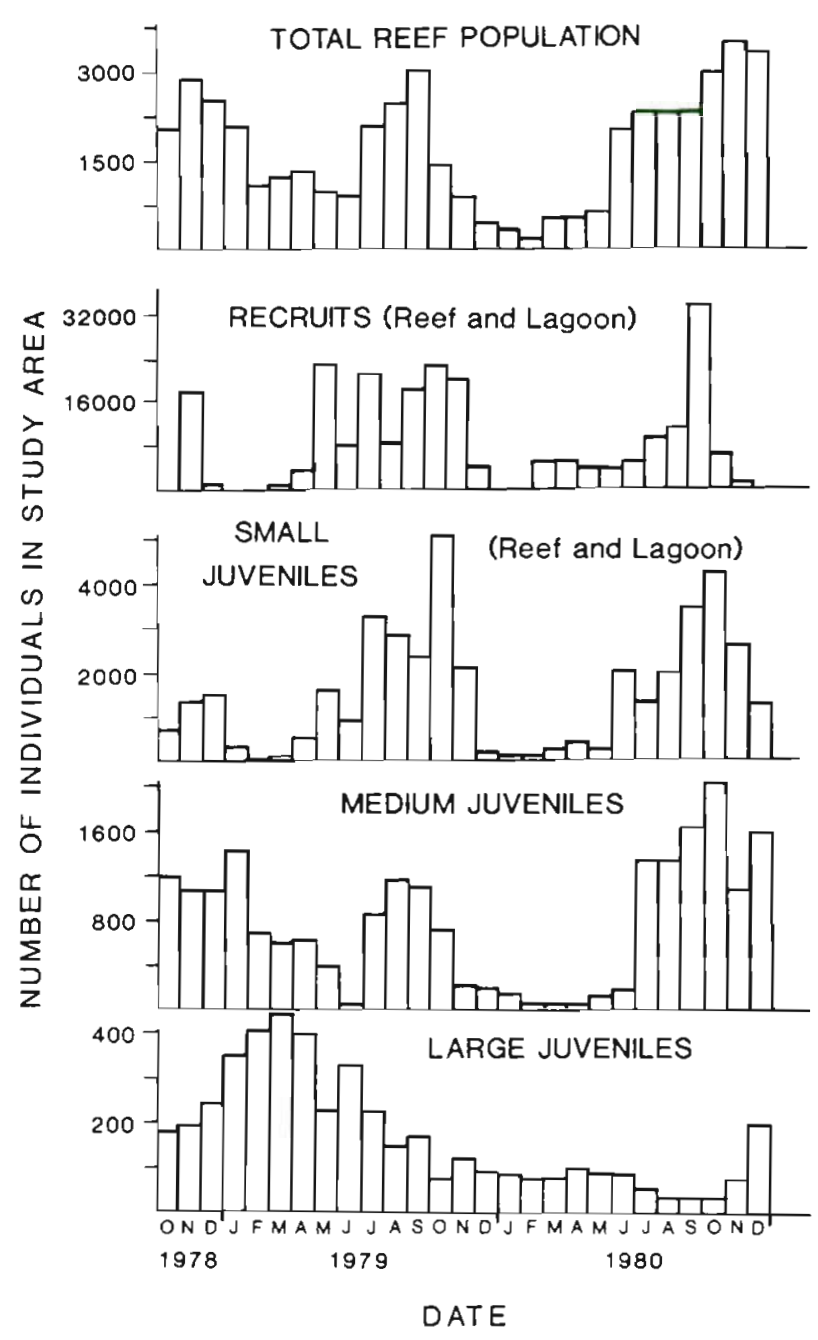

Fig. 2. Haemulon flavolineatum. Fluctuations in numbers of indivduals in each size class present in the study area over the $2 \frac{1}{4}$ yr period. For recruits and small juveniles, the numbers shown are those that occurred in both the reef study area and the lagoon source area. For medium juveniles, large juveniles, and the total reef population, only individuals occupying the reef study area were included (medium and large juveniles do not occur in the lagoon during the daytime). Census data were not available for January 1980 except for recruits in the lagoon source area; the values shown for juvenile size classes were interpolated between the preceding and following months. For the actual sizes and ages represented by these size categories, see Table 1 
Abundances of small juveniles showed dampened versions of the seasonal cycles exhibited by recruits. Peak abundances (1140 to 1800 in the reef study area; 0.43 to 0.68 ind $\mathrm{m}^{-2}$ ) occurred during June to December and small juveniles were rare or absent in January to March. Medium juveniles showed seasonal cycles similar to that of the small juveniles, except that they lagged by approximately 2 mo. Peak abundances ( 1150 to 2000 in the reef study area; 0.43 to 0.75 ind $\mathrm{m}^{-2}$ ) occurred in July to January and lows occurred in February to June.

Abundances of large juveniles did not show seasonal trends (Fig. 2). In the first 5 mo of the study the number of large juveniles doubled and then declined again over the following $5 \mathrm{mo}$. This low abundance was then maintained for the following 15 mo until large juveniles increased in abundance in the last month of the study. Numbers of large juveniles varied by a factor of 6 both within a year and between years in the same month.

\section{Post-settlement survivorship}

Calculations of survivorship rates using 3 different starting dates produced very similar results and only the means will be discussed here. Survivorhip was relatively constant $(8.5$ to $10.9 \%$ ) between sequential size classes (Table 2). However, since the sizes classes represent increasingly broad age ranges, the survivorship rate increases as age past settlement increases (Fig. 3). Survivorship as a function of age can be described by the power function:

$$
\mathrm{S}=5625.5 \times \mathrm{A}^{-1.87} \text { (least squares fit; } \mathrm{r}^{2}=0.97 \text { ) }
$$

where $\mathrm{S}=$ percentage of recruits surviving to age $\mathrm{A}$ (measured in days past settlement). Thus, mortality rates are highest for the youngest and smallest French grunts and lowest for the large juveniles (of the 4 size categories considered here). Overall post-settlement mortality rates were high. For every 10000 recruits that settled into the reef and/or lagoon, only 8 survived to become large juveniles.

Table 2. Haemulon flavolineatum. Percent survivorship between size classes in French grunts

\begin{tabular}{|lccc|}
\cline { 2 - 4 } Initial size class & $\begin{array}{c}\text { Percentage that survive to size class: } \\
\text { Small } \\
\text { juveniles }\end{array}$ & $\begin{array}{c}\text { Medium } \\
\text { juveniles }\end{array}$ & $\begin{array}{c}\text { Large } \\
\text { juveniles }\end{array}$ \\
\hline Recruit & 10.87 & 0.93 & 0.08 \\
Small juvenile & & 8.53 & 0.73 \\
Medium juvenile & & & 8.53 \\
\hline
\end{tabular}

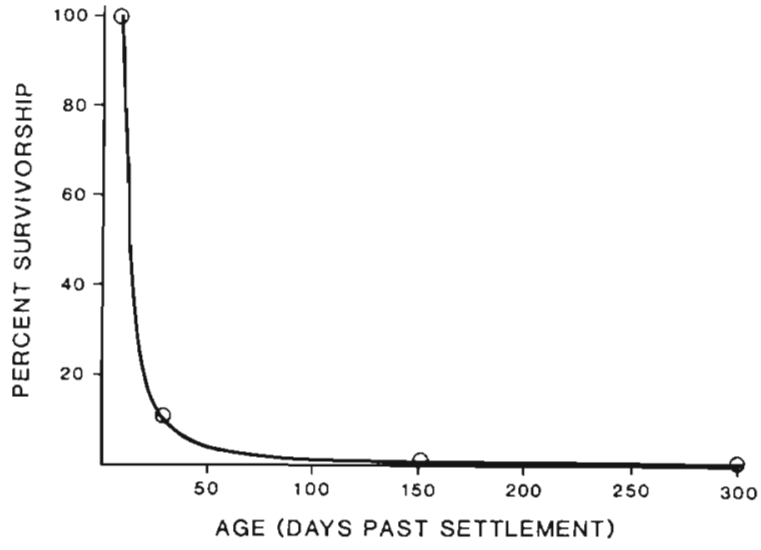

Fig. 3. Haemulon flavolineatum. Percent survivorship of recruits as a function of age (given in days past settlement). The relation can be described by the equation given in the text (Eqn 1)

\section{DISCUSSION}

French grunt larvae metamorphose in the plankton and subsequently settle in very large numbers into sand, seagrass, and reef habitats. In Tague Bay, $95 \%$ of these recruits settled in the lagoon rather than directly on the backreef. Similar spatial patterns of settlement have been described for several other reef fishes. Experiments examining this phenomenon suggest that, for very small fishes, encounter rates with predators are lower, and appropriate shelter more available in the seagrass habitat than in the backreef habitat (Shulman 1985a).

The recruitment rate of French grunts is high, both in absolute numbers $\left[1.8 \mathrm{~m}^{-2} \mathrm{yr}^{-1}\right.$ within Tague Bay lagoon; 44 recruits $\mathrm{yr}^{-1}$ in Tague Bay per $\mathrm{m}^{2}$ of juvenile (backreef) habitat] and relative to the density of large juvenile French grunts on the reef $\left(0.06\right.$ per $\mathrm{m}^{2}$ of backreef). Of the 43 species for which comparable data are available, only 3 show higher annual rates of recruitment relative to available juvenile habitat (Table 3). French grunts recruit over an 8 mo season rather than the 4 mo season for fishes studied near One Tree and Lizard Islands on the Great Barrier Reef. This longer season partially explains the higher annual recruitment; however, comparing only the months of the recruitment season, only 8 or 9 species show higher monthly recruitment rates than that of the French grunt.

How do the annual numbers of recruits compare with the number of eggs being produced in this local population? We can estimate a possible range of egg production if we make the following assumptions. (1) The maximum reproductive life of female French grunts is 6 yr and reproduction begins at 2 yr (Billings \& Munro 1974). (2) The relationship between age and survivorship shown in 'Results' (Fig. 2) can be extended to the 
Table 3. Recruitment rates (per $\mathrm{m}^{2}$ of reef per yr) in coral reef fishes. Several of these studies examined recruitment to very small coral units, with the size of the 'reef' given as a volume. Coral volumes have been converted to reef areas by calculating the surface area of the side and top of a cylinder in which the diameter is equal to the height. For studies which involved looking at different depths or types of corals, we have reported only the highest recruitment rate found for each species

\begin{tabular}{|c|c|c|c|}
\hline Species & $\begin{array}{c}\text { No. of recruits } \\
\mathrm{m}^{-2} \mathrm{yr}^{-1}\end{array}$ & Location & Source \\
\hline \multicolumn{4}{|l|}{ Serranidae } \\
\hline Epinephelus cruentatum & 0.7 & Barbados, Caribbean & Luckhurst \& Luckhurst 1977 \\
\hline Pseudochromis novae-hollandae & 2.0 & One Tree Reef, Australia & Williams \& Sale 1981 \\
\hline Grammidae Gramma loreto & 4.6 & Barbados, Caribbean & Luckhurst \& Luckhurst 1977 \\
\hline \multicolumn{4}{|l|}{ Apogonidae } \\
\hline Apogon cyanosoma & 0.6 & One Tree Reef, Australia & Williams \& Sale 1981 \\
\hline Apogon doederieni & 250.0 & One Tree Reef, Australia & Williams \& Sale 1981 \\
\hline Apogon gracilis & 1.3 & One Tree Reef, Australia & Williams \& Sale 1981 \\
\hline Apogon lachneri & 0.5 & Barbados, Caribbean & Luckhurst \& Luckhurst 1977 \\
\hline Apogon townsendi & 3.5 & Barbados, Caribbean & Luckhurst \& Luckhurst 1977 \\
\hline Cheilodipterus quinquelineata & 3.9 & One Tree Reef, Australia & Williams \& Sale 1981 \\
\hline Fowleria marmoratus & 2.4 & One Tree Reef, Australia & Williams \& Sale 1981 \\
\hline Pha eoptyx conklini & 1.1 & Barbados, Caribbean & Luckhurst \& Luckhurst 1977 \\
\hline Lutjanidae Lutjanus kasmira & 28.7 & Lizard Island, Australia & Sweatman 1985 \\
\hline \multicolumn{4}{|l|}{ Haemulidae } \\
\hline Haemulon flavolineatum & $44.3^{\circ}$ & St. Croix, Caribbean & This report \\
\hline Sciaenidae Equetus punctatus & 0.6 & Barbados, Caribbean & Luckhurst \& Luckhurst 1977 \\
\hline \multicolumn{4}{|l|}{ Chaetodontidae } \\
\hline Chaetodon plebeius & 10.8 & Lizard Island, Australia & Sweatman 1985 \\
\hline \multicolumn{4}{|l|}{ Pomacentridae } \\
\hline Dascyllus aruanus & 0.4 & One Tree Reef, Australia & Williams \& Sale 1981 \\
\hline Dascyllus aruanus & 28.3 & Lizard Island, Australia & Sweatman 1985 \\
\hline Dascyllus reticulatus & 28.3 & Lizard Island, Australia & Sweatman 1985 \\
\hline Chromis cyanea & 2.5 & Barbados, Caribbean & Luckhurst \& Luckhurst 1977 \\
\hline Chromis caerulea & 62.8 & Lizard Island, Australia & Sweatman 1985 \\
\hline Chromis insolatus & 1.0 & Barbados, Caribbean & Luckhurst \& Luckhurst 1977 \\
\hline Chromis nitida & 5.1 & One Tree Reef, Australia & Williams \& Sale 1981 \\
\hline Glyphidodontops flavipinnis & 0.3 & Lizard Island, Australia & Sweatman 1985 \\
\hline Neopomacentrus cyanomos & 17.8 & Lizard Island, Australia & Sweatman 1985 \\
\hline Pomacentrus amboinensis & 0.3 & One Tree Reef, Australia & Williams 1980 \\
\hline Pomacentrus amboinensis & 37.2 & Lizard Island, Australia & Sweatman 1985 \\
\hline Pomacentrus flavicauda & 0.1 & One Tree Reef, Australia & Doherty 1980 \\
\hline Pomacentrus sp. & 0.4 & One Tree Reef, Australia & Williams 1980 \\
\hline Pomacentrus sp. & 1.0 & One Tree Reef, Australia & Williams \& Sale 1981 \\
\hline Pomacentrus sp. & 36.3 & Lizard Island, Australia & Sweatman 1985 \\
\hline Pomacentrus pavo & 2.8 & Lizard Island, Australia & Sweatman 1985 \\
\hline Pomacentrus wardi & 0.1 & One Tree, Reef, Australia & Doherty 1980 \\
\hline Stegastes partitus & 22.5 & Barbados, Caribbean & Luckhurst \& Luckhurst 1977 \\
\hline Stegastes planifrons & 2.8 & Barbados, Caribbean & Luckhurst \& Luckhurst 1977 \\
\hline Labridae Coris variegata & 2.1 & One Tree Reef, Australia & Williams \& Sale 1981 \\
\hline Blenniidae Petroscirtes mitratus & 1.0 & One Tree Reef, Australia & Willians \& Sale 1981 \\
\hline \multicolumn{4}{|l|}{ Congrogadidae } \\
\hline Congrogadus subduscens & 1.1 & One Tree Reef, Australiá & Williams \& Sale 1981 \\
\hline \multicolumn{4}{|l|}{ Gobiidae } \\
\hline Asteropteryx semipunctatus & 20.7 & One Tree Reef, Australıa & Williams \& Sale 1981 \\
\hline Callogobius sp. & 2.3 & One Tree Reef, Australia & Williams \& Sale 1981 \\
\hline Coryphopterus glaucofraenum & 20.8 & Barbados, Caribbean & Luckhurst \& Luckhurst 1977 \\
\hline Coryphopterus lipernes & 13.1 & Barbados, Caribbean & Luckhurst \& Luckhurst 1977 \\
\hline Coryphopterus personatus & 131.2 & Barbados, Caribbean & Luckhurst \& Luckhurst 1977 \\
\hline Gobiodon sp. B & 1.4 & One Tree Reef, Australia & Williams \& Sale 1981 \\
\hline Gnatholepis thompsoni & 20.0 & Barbados, Caribbean & Luckhurst \& Luckhurst 1977 \\
\hline Gnatholepis evelynae & 0.9 & Barbados, Caribbean & Luckhurst \& Luckhurst 1977 \\
\hline Paragobiodon echinocephalus & 11.7 & One Tree Reef, Australia & Williams \& Sale 1981 \\
\hline \multicolumn{4}{|l|}{ Acanthuridae } \\
\hline Acanthurus dussumier & 6.3 & Lizard Island, Australia & Sweatman 1985 \\
\hline \multicolumn{4}{|l|}{ Canthigasteridae } \\
\hline Canthigaster rostrata & 2.8 & Barbados, Caribbean & Luckhurst \& Luckhurst 1977 \\
\hline
\end{tabular}


maximum life span of female French grunts. From Assumptions 1 \& 2 we calculate that a mean of 35 reproductive females produced in this local population should be alive at any one time. (3) Mean number of eggs present in the ovaries of reproductively mature females is 31000 (Billings \& Munro 1974). Recruitment data suggest that spawning occurs on a semilunar basis on quarter moons (McFarland et al. 1985), but spawning frequency is unknown. We will assume that the average reproductive female produces between 62000 (equal to 2 complete spawns $\mathrm{yr}^{-1}$ ) and 806000 (26 quarter moon complete spawns $\mathrm{yr}^{-1} \times 31000$ ) eggs $\mathrm{yr}^{-1}$.

With these assumptions, we estimate there are between 20 and 240 eggs produced for every recruit arriving in this population. This ratio is far lower than the one found for Pomacentrus wardi on the Great Barrier Reef (Doherty 1980). Because Tague Bay is not a closed system, it is impossible to estimate larval mortality rates from the ratio of eggs to recruits in this population. However, we can conclude that either or both of the following must be true: (1) Tague Bay is a sink for French grunt recruits produced by other populations; and/or (2) larval survivorship is high in this species (probably greater than $0.6 \%$ ). French grunts have a short planktonic life (14 d) compared to most other reef fishes (Brothers et al, 1983, Brothers \& Thresher 1985, Victor 1986a); it is not improbable that larval survivorship should be higher as a result.

In addition to high recruitment rates, French grunts also exhibit high post-settlement mortality rates with less than $0.1 \%$ of recruits surviving to age $1 \mathrm{yr}$. We suspect that the major source of mortality in young grunts is predation. We have observed or filmed predation on recruits and small juveniles by snappers Lutjanus mahogoni, L. buccanella, Ocyurus chrysurus, and jack Caranx ruber (Shulman et al. 1983, Ogden unpubl. data). Predation on older juvenile grunts by a lizardfish
Synodus intermedius and the peacock flounder Bothus lunatus has also been reported (Helfman et al. 1982). Adult snappers and jacks, frequently foraging in schools, will make repeated passes through groups of small grunts, attempting to strike on each pass. Much of this predatory activity appears to take place during twilight, a time that prey are hypothesized to be particularly vulnerable (Hobson 1968, 1972, McFarland \& Munz 1976, Helfman et al. 1982, Helfman 1986).

Mortality rates (per unit time) during the benthic life stage in French grunts were highest in the youngest/ smallest classes and decreased dramatically with increasing age and size (Fig. 3). Smaller grunts are presumably more vulnerable to predation than larger individuals because: (1) they swim more slowly, (2) they have lower visual acuity (Munz \& McFarland 1973), and (3) they may be in the appropriate prey size range for more predators. Additionally, post-metamorphic developmental problems may contribute to early mortality in the benthic life-stage.

A comparison with the very limited data available on benthic mortality rates in other reef fishes demonstrates that French grunts show the highest rate yet reported (Table 4). Ninety \% of French grunt recruits die within the first month after settlement. In sharp contrast, 2 species of West Pacific pomacentrids experience only $20 \%$ mortality during the first month of benthic life (Table 4). These marked differences in benthic mortality continue with age. Only $0.1 \%$ of French grunts survive to $1 \mathrm{yr}$, while $2 \%$ of recruiting Thalassoma bifasciatum, $20 \%$ of Pomacentrutus flavicauda, and $75 \%$ of $P$. wardi survive to that age (Table 4). These differences in early mortality rates could be due to a variety of factors, among which are differences in size, behavior, abundance (affecting the development of search images among predators), or predator densities.

Several recent studies have provided evidence for

Table 4. Post-settlement survivorship in coral reef fishes. Estimates of survivorship to ages of 1 mo, 1 yr and to age of first reproduction are given where available. -: no data available

\begin{tabular}{|c|c|c|c|c|c|c|}
\hline \multirow[t]{2}{*}{ Species } & \multicolumn{3}{|c|}{ Recruits surviving to: } & \multirow{2}{*}{$\begin{array}{c}\text { Age at } \\
\text { 1st repro. }\end{array}$} & \multirow[t]{2}{*}{ Location } & \multirow[t]{2}{*}{ Source } \\
\hline & $1 \mathrm{mo}$ & $1 \mathrm{yr}$ & 1st repro. & & & \\
\hline \multicolumn{7}{|l|}{ Haemulidae } \\
\hline Haemulon flavolineatum & $10 \%$ & $0.1 \%$ & $0.01 \%$ & $2 \mathrm{yr}^{*}$ & St. Croix, Caribbean & This report \\
\hline \multicolumn{7}{|l|}{ Pomacentridae } \\
\hline Pomacentrus sp. & $80 \%$ & - & - & - & One Tree, Australia & Williams 1980 \\
\hline Pomacentrus amboinensis & $80 \%$ & - & - & - & One Tree, Australia & Williams 1980 \\
\hline P. flavicauda $\cdots$ & - & $20 \%$ & $20 \%$ & $1 \mathrm{yr} ?$ & One Tree, Australia & Doherty 1982 \\
\hline P. wardi & - & $75 \%$ & $75 \%$ & 1 Yr? & One Tree, Australia & Doherty 1983 \\
\hline \multicolumn{7}{|l|}{ Labridae } \\
\hline Thalassoma bifasciatum & $28 \%$ & $2 \%$ & $9 \%$ & $3 \mathrm{mo}$ & Panama, Caribbean & Victor $1986 b$ \\
\hline
\end{tabular}


both recruitment limitation and a lack of resource limitation in several species of reef fishes. Two kinds of evidence have been used to adduce the presence of recruitment limitation: (1) a lack of density-dependent post-settlement mortality (Doherty 1982, Victor 1983, 1986b), and (2) a very low recruitment rate, barely sufficient to replace the adult population (Williams 1980. Doherty 1983) or allow a numerical response to increases in benthic resources (Wellington \& Victor 1985). Do either of these 2 conditions characterize the French grunt population we have studied?

In the Tague Bay population, over 1000 recruits arrive each year for every large juvenile living on the reef. Though the number of adults produced in the reef study area is unknown (due to emigration), we estimate, using the survivorship and longevity assumptions discussed above, that the ratio between the annual number of recruits (to the reef study area and the lagoon source area) and the number of adults is 1700 to 1 . In striking contrast are studies on several species of damselfishes at One Tree Island on the Great Barrier Reef. Williams (1980) and Doherty (1983) found ratios of 1 recruit $y^{-1}$ for every 2 to 6 adult Pomacentrus amboinensis, Pomacentrus sp., and P. wardi. What causes these differences in recruitment rates? Differences between geographic locations appear to be part of the explanation. Sweatman (1985), working at Lizard Island on the northern section on the Great Barrier Reef, found up to 100 times the density of recruiting Dascyllus aruanus, Pomacentrus amboinensis, and Pomacentrus sp. than were found at One Tree Island (Table 3). Geographic and oceanographic differences between the locations probably account for different exposure to water masses carrying fish larvae (Sweatman 1985). Even more importantly, we can presume that there are large biological differences between the eggs and larvae of different species that result in different rates and patterns of planktonic mortality and subsequent recruitment success. However, at present, larval characteristics affecting planktonic survivorship remain unstudied. In addition to differences in larval mortality, species will vary in the number of eggs produced per female per year Thresher (1982) has reported a lower mean egg size in Caribbean fishes with demersal eggs, than in related species from the tropical western Pacific. He has hypothesized that, for a given body size, Caribbean species with demersal eggs will produce more larvae per female per year and would be expected to show higher recruit/adult ratios than confamilial species from the tropical Pacific. This hypothesis has not been tested.

Is there evidence that the benthic mortality in French grunts is density dependent? This study was not designed to test for the presence of absence of densitydependent mortality or to determine the effects of resource availability on benthic mortality. However, aggression in grunt schools has been observed to affect individual access to shelter sites (McFarland \& Hillis 1982, Shulman 1985b); these behaviors might possibly result in density-dependent mortality, but that has not yet been demonstrated.

Regardless of whether or not benthic mortality in French grunts is density-dependent, we can still consider the relative importance of recruitment versus benthic mortality in controlling the adult (or in our case, the large-juvenile) population on the reef. To accomplish this, we propose the following criterion, which has general applications for determining the relative importance (strengths) of multiple limiting factors. The criterion is the relative sensitivity of adult population size to proportionate changes in the limiting factors or processes. To apply this criterion, we need a model that describes the population dynamics for the species in question. For French grunts, because we do not know whether any or all of the sources of benthic mortality are density-dependent, we will make the conservative assumption that benthic mortality is completely density-independent. (Therefore, we are assuming that recruitment is a limiting factor). With this assumption, the population size of large juvenile French grunts can be described by the equation:

$$
\mathrm{LJ}=(1-\mathrm{m}) \mathrm{R}
$$

where $\mathrm{LJ}=$ number of large juveniles; $\mathrm{m}=$ mortality rate between settlement and large juvenile size/age;

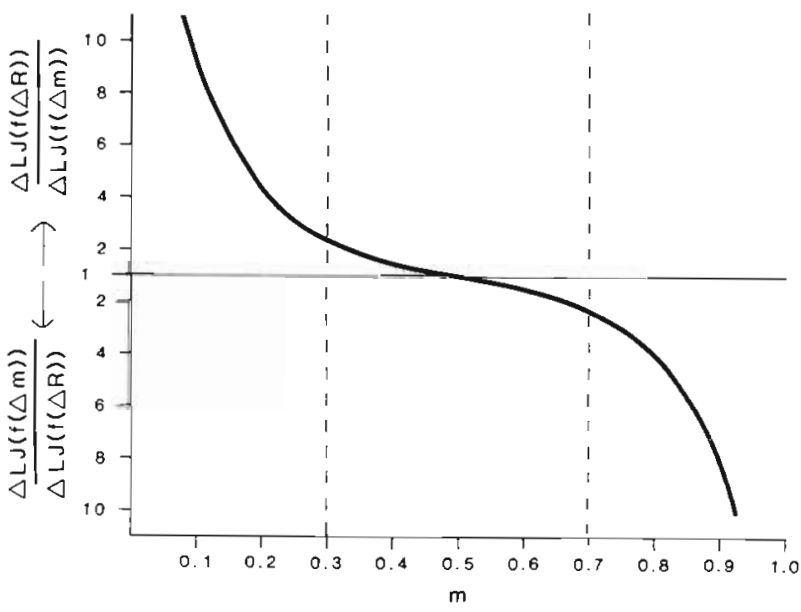

Fig. 4. Sensitivity of benthic large juvenile (L) population size to proportionate changes in recruitment $(R)$ versus post-settlement mortality $(\mathrm{m})$ rates, according to a model in which $\mathrm{LJ}=$ $(1-\mathrm{m}) \mathrm{R}$ (see text). When $\mathrm{m}<0.5$, changes in recruitment produce a greater change in large juvenile population size than do changes in the mortality rate. When $\mathrm{m}>0.5$ the reverse is true. These differences are especially marked when $m$ is very small (less than 0.3 ) or very large (greater than 0.7 ) 
and $\mathrm{R}=$ number of recruits that settled in the cohort that produced these large juveniles. Is LJ more sensitive to proportionate changes in the mortality rate or in the recruitment rate?

We are interested in the ratio of the change in $\mathrm{LJ}$ as a function of a change in $m$ to the change in $L J$ as a function of a proportionate change in $\mathrm{R}$. The change in $\mathrm{LJ}$ that results from a small change $(=\delta)$ in $\mathrm{m}$ is:

$$
\begin{aligned}
\Delta \operatorname{LJ}(f(\Delta m)) & =[R(1-m(1-\delta))]-[R(1-m)] \\
& =m R \delta
\end{aligned}
$$

The change in LJ resulting from an equivalent proportionate change in $\mathrm{R}$ is:

$$
\begin{aligned}
\Delta \mathrm{LJ}(\mathrm{f}(\Delta \mathrm{R})) & =[\mathrm{R}(1+\delta)(1-\mathrm{m})]-[\mathrm{R}(1-\mathrm{m})] \\
& =(1-\mathrm{m}) \mathrm{R} \delta
\end{aligned}
$$

Therefore, the equation for the ratio of interest is:

$$
\frac{\Delta \mathrm{LJ}(\mathrm{f}(\Delta \mathrm{m}))}{\Delta \mathrm{LJ}(\mathrm{f}(\Delta \mathrm{R}))}=\frac{\mathrm{m}}{(1-\mathrm{m})}
$$

and is independent of the value of $R$. The relation between this ratio (or its inverse, if it is less than 1) and the mortality rate is shown in Fig. 4. For a broad middle range of values of $m$ (approximately between 0.3 and $0.7)$, the effects of proportionate changes in $R$ and $m$ are relatively similar. For $m$ values less than 0.3 , changes in the recruitment rate have a far greater effect on the older benthic population than does a proportionately equal change in the mortality rate. For $m$ values greater than 0.7 the reverse is true.

For French grunts, the mortality rate between settlement and large juvenile age is 0.992; a change in the mortality rate will have a 100 times greater effect on the number of large juveniles than will the same proportionate change in the number of recruits. Using this criterion, it is clear that whatever factors are responsible for the high benthic mortality, those factors are far more important to the benthic population dynamics in French grunts than is the recruitment rate.

Using our criterion, can we make the same kind of evaluation of the relative sensitivity of adult population size to benthic mortality versus recruitment for other species of reef fishes? Pomacentrus wardi at One Tree Reef appears to have a very low post-settlement mortality rate, about 0.25 in the first year (Table 4); recruitment probably more strongly controls adult population sizes than does benthic mortality. The other 2 species for which we have post-settlement mortality information have much higher mortality rates: $92 \%$ of Thalassoma bifasciatum and at least $80 \%$ of $P$. flavicauda recruits do not survive to reproductive age (Table 4 ). If a model similar to the one discussed above describes the local population dynamics in these species, then adult population size will be far more sensitive to changes in benthic mortality than to changes in recruitment. Previous authors have stressed the importance of recruitment in limiting benthic population size and there is good evidence that benthic mortality is, in fact, densityindependent in all 3 of these species (Doherty 1982, Victor 1983, 1986b). However, for the latter 2 species, the effects of benthic mortality on adult population size have been largely ignored. Though evidence supports the existence of recruitment limitation, its effects, relative to benthic mortality (which also limits adult populations), are minor according to our criterion. This analysis suggests that we need to understand further how food resources, competitors, shelter, number and size of predators and composition of the predator assemblage contribute to, and control, benthic mortality.

Acknowledgements. We thank W. McFarland for sharing his knowledge, enthusiam and ideas about French grunts, A. R. Palmer for helping with a portion of the data analysis, and $C$. McIvor, J. Morin, J. Neigel, D. R, Robertson, and M. Slatkin for making valuable comments on the manuscript. This is Contribution No. 138 from the West Indies Laboratory, Fairleigh Dickinson University.

\section{LITERATURE CITED}

Adey, W. H. (1975). The algal ridges and coral reefs of St. Croix, their structure and development. Atoll Res. Bull. 187: $1-67$

Billings, V C., Munro, J. L. (1974). The biology, ecology, exploitation and management of Caribbean reef fishes. Part Ve. The biology, ecology and bionomics of Caribbean reef fishes: Pomadasyidae (grunts). Scientific Report of the ODA/UWI Fisheries Ecology Research Project, Port Royal Marine Laboratory, Jamaica, 1969-1973. Kingston, Jamaica

Brothers, E. B., McFarland, W N. (1981). Correlations between otolith microstructure, growth, and life history transitions in newly recruited French grunts (Haemulon flavolineatum (Desmarest), Haemulidae). Rapp. P.-v. Réun. Cons. Int. Explor. Mer 178: 369-374

Brothers, E. B., Thresher, R. E. (1985). Pelagic duration, dispersal, and the distribution of Indo-Pacific coral-reef fishes. In: Reaka, M. (ed.) The ecology of coral reefs Vol. 3 (1). Symposia Series for Undersea Research, NOAA's Undersea Research Program, p. 53-69

Brothers, E. B., Williams, D. McB., Sale, P. F. (1983). Length of larval life in twelve families of fishes at 'One Tree Lagoon'. Great Barrier Reef, Australia, Mar. Biol. 76: 319-324

Doherty, P. J. (1980). Biological and physical constraints on the populations of two sympatric territorial damselfishes on the southern Great Barrier Reef. Ph. D. dissertation, University of Sydney, Sydney, Australia

Doherty, P. J. (1982). Some effects of density on the juveniles of two species of tropical, territorial damselfish. J. exp. mar Biol. Ecol. 65: 249-261

Doherty, P. J. (1983). Tropical territorial damselfishes: is density limited by aggression or recruitment? Ecology 64 $176-190$ 
Gaines, S., Roughgarden, J. (1985). Larval settlement rate: a leading determinant of structure in an ecological community of the marine intertidal zone. Proc natl Acad. Sci. U.S.A. $82: 3707-3711$

Helfman, G. S. (1986). Behavioral responses of prey fishes during predator-prey interactions. In: Feder, M. E., Lauder, G. V. (ed.) Predator-prey relationships: perspectives and approaches from the study of lower vertebrates. The University of Chicago Press. Chicago, p. 135-157

Helfman, G. S., Meyer, J. L., McFarland, W. N. (1982) The ontogeny of twilight migration patterns in grunts (Pisces: Haemulidae). Anim. Behav. 30:317-326

Hobson, E. S. (1968). Predatory behavior of some shore fishes in the Gulf of California. U. S. Bur. Sport Fish. Wildlife, Res. Rep. 73: 1-92

Hobson, E. S. (1972). Activity of Hawaiian reef fishes during evening and morning transitions between daylight and darkness. Fish. Bull. U. S. 70: 715-740

Luckhurst, B. E., Luckhurst, K. (1977). Recruitment patterns of coral reef fishes on the fringing reefs of Curaçao, Netherlands Antilles. Can J. Zool. 55: 681-689

McFarland, W. N., Munz, F. W. (1976). The visible spectrum during twilight and its implications to vision. In: Evans, G. C., Bainbridge, R., Rackham, O. (ed.) Light as an ecological factor: II. Blackwell, Oxford, p. 249-270

McFarland, W. N., Hillis, Z.-M. (1982). Observations on agonistic behavior between members of juvenile French and white grunt schools - Family Haemulidae. Bull. mar Sci. 31: 255-268

McFarland, W. N., Ogden, J. C., Lythgoe, J. N. (1979). The influence of light on the twilight migrations of grunts. Env. Biol. Fish. 4: 9-22

McFarland, W. N., Brothers, E. B., Ogden, J. C., Shulman, M. J., Bermingham, E. L., Kotchian-Prentiss, N. M. (1985). Recruitment patterns in young French grunts, Haemulon flavolineatum (family Haemulidae), at St. Croix, Virgin Islands. Fish. Bull. U. S. 83: 151-161

Munz, F. W., McFarland, W N. (1973). The significance of spectral position in the rhodopsins of tropical marine fishes. Vision Res. 13: 1829-1874

Ogden, J. C. (ed.) (1972). An ecological study of Tague Bay reef, St. Croix, U. S. Virgin Islands. Spec. Publ. Mar. Biol. No. 1, West Indies Laboratory, Fairleigh Dickinson University, Christiansted, St. Croix, U. S. Virgin Islands

Ogden, J. C., Ehrlich, P. R. (1977). The behavior of heterotypic resting schools of juvenile grunts (Pomadasyidae). Mar Biol. 42: 273-280

Robblee, M. B. (1986). The organization of the nocturnal fish fauna of a tropical seagrass feeding ground. Doctoral dissertation, University of Virgina, Charlottesville

Sale, P. F. (1980). The ecology of fishes on coral reefs, Oceangr. mar. Biol. A. Rev. 18: 367-421

Shulman, M. J. (1984). Resource limitation and recruitment patterns in a coral reef fish assemblage. J. exp. mar. Biol. Ecol. 74: 85-109

Shulman, M. J. (1985a). Recruitment of coral reef fishes: effects of distribution of predators and shelter. Ecology 66 : 1056-1066

Shulman, M. J. (1985b). Coral reef fish assemblages: intraand interspecific competition for shelter sites. Env. Biol. Fish. 13: 81-92

Shulman, M. J., Ogden, J. C., Ebersole, J. P., McFarland, W N., Miller, S. L., Wolf, N. F. (1983). Priority effects in the recruitment of coral reef fishes. Ecology 64: 1508-1513

Sweatman, H. P. A. (1985). The influence of adults of some coral reef fishes on larval recruitment. Ecol. Monogr. 55: $469-485$

Thresher, R. E. (1982). Interoceanic differences in the reproduction of coral-reef fishes. Science 218: 70-72

Underwood, A. J., Denley, E. J. (1984). Paradigms, explanations and generalizations in models for the structure of intertidal communities on rocky shores. In: Strong. D. R., Simberloff, D., Abele, L. G., Thistle, A. B. (ed.) Ecological communities: conceptual issues and the evidence. Princeton Univ. Press, Princeton, New Jersey, p. 151-180

Victor, B. C. (1983). Recruitment and population dynamics of a coral reef fish. Science 219: 419-420

Victor, B. C. (1986a). The duration of the planktonic larval stage of one hundred species of Pacific and Atlantic wrasses (Family Labridae). Mar Biol. 90: 317-326

Victor, B. C. (1986b). Larval settlement and juvenile mortality in a recruitment-limited coral reef fish population. Ecol Monogr. 56: 145-160

Wellington, G. M., Victor, B. C. (1985). El Niño mass coral mortality: a test of resource limitation in a coral reef damselfish population. Oecologia (Berl.) 68: 15-19

Williams, D. McB. (1980). Dynamics of the pomacentrid community on small patch reefs in One Tree Lagoon (Great Barrier Reef). Bull. mar. Sci. 30: 159-170

Williams, D. McB., Sale, P. F. (1981). Spatial and temporal patterns of recruitment of juvenile coral reef fishes to coral habitats within One Tree Lagoon, Great Barrier Reef. Mar Biol. 65: 245-253

Yoshioka, P. M. (1982). Role of planktonic and benthic factors in the population dynamics of the bryozoan Membranipora membranacea. Ecology 63: 457-468 